\title{
Resource stoichiometric and fertility in soil
}

\author{
Tida $\mathrm{Ge}^{1} \cdot$ Yu Luo ${ }^{2} \cdot$ Bhupinder Pal Singh ${ }^{3}$ \\ Published online: 1 October 2020 \\ (C) Springer-Verlag GmbH Germany, part of Springer Nature 2020
}

Ecological stoichiometry has been a showpiece of ecological theory for over 80 years, and the stoichiometric approach used elemental ratios to predict elemental cycling, for example, organic matter decomposition and nutrient retention from microbial cell to ecosystem scales (Allen and Gillooly 2009; Zechmeister-Boltenstern et al. 2015). Most recent stoichiometry studies are limited in aquatic environments. The stoichiometric approach requires considering biogeochemical fluxes along with the terrestrial system. Nutrient availability and its $\mathrm{C}: \mathrm{N}: \mathrm{P}$ stoichiometric ratios are critical in the regulation of nutrient transformation, substrate C (e.g., plant rhizodeposition), and soil organic $\mathrm{C}$ (SOC) mineralization in agroecosystems (Zhu et al. 2018; Cui et al. 2020). Agriculture practice has led to a significant increase in anthropogenic inputs of nutrients and C into ecosystems (Ge et al. 2017; Wei et al. 2019). The effects of resource input on soil $\mathrm{C}$ dynamics have been interpreted using the theories of "nutrient mining" or "microbial stoichiometry" (Chen et al. 2014). These theories predict that activity, biomass, and composition of microbial communities are driven by microbial demand for resources, like C, energy, and nutrients. Stoichiometry allows a deep understanding of biological mechanisms of elemental cycling at different scales, from cellular metabolism to terrestrial ecosystem (ZechmeisterBoltenstern et al. 2015). However, studies on the relationship of stoichiometry of soil nutrients, plant, and microorganisms with

Tida Ge

getida@nbu.edu.cn

1 State Key Laboratory for Managing Biotic and Chemical Threats to the Quality and Safety of Agro-products, Key Laboratory of Biotechnology in Plant Protection of Ministry of Agriculture and Zhejiang Province, Institute of Plant Virology, Ningbo University, Ningbo 315211, China

2 Institute of Soil and Water Resources and Environmental Science, Zhejiang Provincial Key Laboratory of Agricultural Resources and Environment, Zhejiang University, Hangzhou 310058, Zhejiang, China

3 NSW Department of Primary Industries, Elizabeth Macarthur Agricultural Institute, Menangle, NSW 2568, Australia elemental cycling in terrestrial ecosystems, such as C cycling, are still limited.

This special issue aims to bring together a few studies to provide quantitative and mechanistic insights into fundamental processes that govern nutrient and $\mathrm{C}$ dynamics, like substrate-derived $\mathrm{C}$ decomposition and priming of SOC mineralization, with implications for soil $\mathrm{C}$ storage. The cuttingedge techniques, including $\mathrm{C}$ isotope, biomarkers, and molecular biology (with high-throughput gene sequencing), have been applied to address the effects of agricultural practices and global environmental changes on soil $\mathrm{C}$ dynamics.

Five papers have been accepted from 18 submitted manuscripts around the world, though most of the accepted ones were studies from China and one from Australia, including collaborations with national and international colleagues. New findings from these papers enhance our understanding of biogeochemical processes of elemental cycling in terrestrial ecosystems by unravelling the underlying stoichiometric mechanisms. These papers applied $\mathrm{N}$ or $\mathrm{N}$ and $\mathrm{P}$ fertilization in soils to study the stoichiometric flexibility of microbes, plants, and soil and reveal the stoichiometric mechanisms in soil biogeochemical processes, such as $\mathrm{C}$ sequestration. Fan et al. (2020) showed that depletion of SOC was greater with increasing nutrient ( $\mathrm{N}$ and $\mathrm{P}$ ) addition rates to farmland aggregates, while the depletion in woodlot aggregates showed no differences among nutrient treatments, suggesting that microbial activity was nutrient-limited in farmland aggregates. They also found that differences in $\mathrm{C}$ mineralization among aggregate size classes were significant in woodlot soil but not in farmland soil. Wei et al. (2020) suggested bacteria shifted their community composition and increased SOC mineralization to maintain the microbial biomass $\mathrm{C}: \mathrm{N}: \mathrm{P}$ stoichiometric balance in response to changes in resource stoichiometry. Liu et al. (2020) also elucidated the relationship between the stoichiometry of soil microbes, plants, and soil nutrients. They found microbial stoichiometry changes were driven by $\mathrm{N}$ not $\mathrm{C}$ and $\mathrm{P}$ concentrations in their long-term $\mathrm{N}$ fertilization field experiment. Structural equation modelling revealed that the addition of $\mathrm{N}$ predominantly controlled soil microbial $\mathrm{C} / \mathrm{N}$ and N/P ratios through plant leaf and root stoichiometry, but 
not the composition of the plant community and main microbial groups. Their findings suggest that the $\mathrm{N}$-induced changes in plant resource stoichiometry are the core drivers of soil microbial stoichiometry responses to $\mathrm{N}$ deposition. Fang et al. (2020) applied four different organic amendments with and without nutrients and gypsum. They found that balancing the nutrient stoichiometry of organic amendments (OAs) via nutrient inputs increased microbial biomass $\mathrm{C}$ (MBC) but not C-use efficiency (CUE). The input of gypsum accompanied by OAs had no impact on either MBC or CUE. This study concluded that balanced $\mathrm{C} /$ nutrient stoichiometry and labile $\mathrm{C}$ content of OAs are critical properties to control their effect on $\mathrm{C}$ mineralization, $\mathrm{MBC}$, and $\mathrm{CUE}$, with implications for soil $\mathrm{C}$ storage upon amendment into a poorly structured sodicsubsoil. Song et al. (2020) applied stoichiometry in a forest ecosystem while suggesting a potentially positive plant-soil feedback in Populus purdomii and a negative one in Sinojackia rehderiana with an increasing $\mathrm{N}$ availability. $P$. purdomii showed a more efficient $\mathrm{N}$ uptake capacity and water use efficiency compared with $S$. rehderiana under $N$ application. These observations can explain why P.purdomii replaces $S$. rehderiana along primary succession with an increasing soil age and $\mathrm{N}$ availability in a subalpine glacier forefield. Their results indicated that stoichiometric flexibility occurred in tree seedlings at the early stage of succession, which influenced biogeochemical cycling, soil microbial community diversity, and tree species replacement.

Finally, the guest editors would like to express our sincere thanks to all authors who submitted their studies, irrespective of being accepted or not to this special issue. We also appreciate all reviewers, responsible editors, and the Editor-in-Chief of Paolo Nannipieri from the Biology and Fertility of Soils for their continuous assistance in making this special issue success.

\section{References}

Allen AP, Gillooly JF (2009) Towards an integration of ecological stoichiometry and the metabolic theory of ecology to better understand nutrient cycling. Ecol Lett 1:369-384
Chen R, Senbayram M, Blagodatsky S, Myachina O, Dittert K, Lin X, Blagodatskaya E, Kuzyakov Y (2014) Soil C and N availability determine the priming effect: microbial $\mathrm{N}$ mining and stoichiometric decomposition theories. Glob Chang Biol 20:2356-2367

Cui J, Zhu Z, Xu X, Liu S, Jones D, Kuzyakov Y, Shibistova O, Wu J, Ge $\mathrm{T}$ (2020) Carbon and nitrogen recycling from microbial necromass to cope with $\mathrm{C}: \mathrm{N}$ stoichiometric imbalance by priming. Soil Biol Biochem 142:107720

Fan R, Du J, Liang A, Lou J, Li J (2020) Carbon sequestration in aggregates from native and cultivated soils as affected by soil stoichiometry. Biol Fertil Soils. https://doi.org/10.1007/s00374-020-01489-2

Fang Y, Singh BP, Collins D, Armstrong R, Zwieten LV, Tavakkoli E (2020) Nutrient stoichiometry and labile carbon content of organic amendments control microbial biomass and carbon-use efficiency in a poorly structured sodic-subsoil. Biol Fertil Soils 56:219-233

Ge T, Li B, Zhu Z, Hu Y, Yuan H, Dorodnikov M, Jones D, Wu J, Kuzyakov Y (2017) Rice rhizodeposition and its utilization by microbial groups depends on $\mathrm{N}$ fertilization. Biol Fertil Soils 53:37-48

Liu X, Lamb EG, Zhang S (2020) Nitrogen addition impacts on soil microbial stoichiometry are driven by changes in plant resource stoichiometry not by the composition of main microbial groups in an alpine meadow. Biol Fertil Soils 56:261-271

Song M, Yu L, Fu S, Korpelainen H, Li C (2020) Stoichiometric flexibility and soil bacterial communities respond to nitrogen fertilization and neighbor competition at the early stage of primary succession. Biol Fertil Soils. https://doi.org/10.1007/s00374-020-01495-4

Wei X, Zhu Z, Liu Y, Luo Y, Deng Y, Xu X, Liu S, Richter A, Guggenberger G, Wu J, Ge T (2020) C:N:P stoichiometry regulates soil organic carbon mineralization and concomitant shifts in microbial community composition in paddy soil. Biol Fertil Soils. https:// doi.org/10.1007/s00374-020-01468-7

Wei X, Zhu Z, Wei L, Wu J, Ge T (2019) Biogeochemical cycles of key elements in the paddy-rice rhizosphere: microbial mechanisms and coupling processes. Rhizosphere 10:100145

Zechmeister-Boltenstern S, Keiblinger KM, Mooshammer M, Peñuelas J, Richter A, Sardans J, Wanek W (2015) The application of ecological stoichiometry to plant-microbial-soil organic matter transformations. Ecol Monogr 85:133-155

Zhu Z, Ge T, Luo Y, Liu S, Xu X, Tong C, Shibistova O, Guggenberge G, Wu J (2018) Microbial stoichiometric flexibility regulates rice straw mineralization and its priming effect in paddy soil. Soil Biol Biochem 121:67-76

Publisher's note Springer Nature remains neutral with regard to jurisdictional claims in published maps and institutional affiliations. 